\title{
A Pedra do Reino e a Carnavalização
}

\section{The Stone of the Kingdom and the Carnivalization}

\section{José Nogueira da Silva ${ }^{1}$}

Resumo: Neste artigo, buscamos analisar o Romance d'A Pedra do Reino e o Príncipe do Sangue do vai-e-volta de Ariano Suassuna. Para isso a Cultura popular na Idade Média: o contexto de François Rabelais teve importância basilar, uma vez que, no Movimento Armorial de Suassuna, as culturas erudita e popular efetuam um diálogo constante, assim como as obras cômicas Gargântua e Pantagruel analisadas por Mikhail Bakhtin, o que permitirá não somente uma reafirmação da proposta Armorial sob os moldes bakhtinianos, mas também uma reflexão acerca da desconstrução do binarismo entre o que se compreender por erudito e popular em nossa literatura.

Palavras-chave: carnavalização, erudito, popular.

Abstract: In this article, we seek to analyze the Romance of the Stone of the Kingdom and the Prince of Coming-and-Going Blood (Romance d'A Pedra do Reino e o Príncipe do Sangue do vai-e-volta) of Ariano Suassuna. For this the Popular culture in the Middle Ages: the context of François Rabelais had fundamental importance since, in the Armorial Movement of Suassuna, the classical and popular cultures perform a constant dialogue, then like the comic works Gargantua and Pantagruel analyzed by Mikhail Bakhtin, what allow not only a reaffirmation of the Armorial proposal from the Bakhtinian molds, but also a reflection on the deconstruction of the binary between what is understoood by classical and popular in our literature.

Key-words: carnivalization, scholar, popular.

A presente discussão tem como intuito investigar o Romance d'A Pedra do Reino e o Príncipe do Sangue do vai-e-volta, romance de Ariano Suassuna. Levaremos em consideração seus aspectos burlescos, para isso servirá de embasamento teórico a obra Cultura popular na Idade Média: o contexto de François Rabelais de Mikhail Bakhtin, o que permitirá um reflexão mais sólida a respeito da comicidade da obra e como ela se dá sob a ótica da carnavalização.

Faz-se pertinente uma investigação acerca da obra de Bakhtin e a carnavalização descrita pelo mesmo. Isso possibilitará uma melhor compreensão do ponto de vista que o presente trabalho abordará. A obra de Rabelais foi escrita no início do Renascimento, mesmo assim, Bakhtin deu ênfase aos aspectos medievais, inclusive à atmosfera sacra do momento. Isso ressalta a importância da escrita rabelaisiana, pois traz elementos da cultura popular medieval, principalmente dos carnavais,

\footnotetext{
1 Mestrando em Estudos Literários pelo Programa de Pós-Graduação em Letras e Linguística da Universidade Federal de Alagoas (2014).
} 
festas nas quais os elementos sagrados eram rebaixados e sujeitos a serem alvo de burla durante as festividades.

O romance de Ariano Suassuna foi lançado em 1971; seria anacrônica uma analogia que não levasse em conta os contrastes entre obras de períodos tão distintos se a compararmos ao trabalho de Rabelais. No entanto, a escrita literária também é um ciclo que inova e se renova em diálogo constante com obras anteriores, daí a carnavalização encontrada em Rabelais por Bakhtin servir de alicerce teórico para a dissecação de uma obra literária.

\section{O delineamento da Carnavalização}

A teoria da cultura cômica popular na Idade Média e no Renascimento é descrita brevemente por Bakhtin na obra Problemas na poética de Dostoiévski² (2011). A versão mais abrangente e inovadora é encontrada na sua tese de doutorado, que mais tarde foi por ele revisada e tornou-se $A$ cultura popular na Idade Média e no Renascimento: o contexto de François Rabelais. Nessa pesquisa, o autor faz uma análise das obras Gargantua e Pantagruel, escrita pelo Francês François Rabelais (1490-1553). Bakhtin procura analisar as influências populares que permeiam a escrita de Rabelais.

Logo na introdução da obra, o autor revela sua finalidade de investigar influência da cultura popular na escrita de François Rabelais, estabelecendo divisões específicas dessas influências.

As múltiplas manifestações dessa cultura podem subdividir-se em três grandes categorias:

1. As formas dos ritos e espetáculos (festejos carnavalescos, obras cômicas representadas nas praças públicas, etc.);

2. Obras cômicas verbais (inclusive as paródicas) de diversa natureza: orais e escritas, em latim ou em língua vulgar;

3. Diversas formas e gêneros do vocabulário familiar e grosseiro (insultos, juramentos, blasões populares, etc).

Essas três categorias que, na sua heterogeneidade, refletem um mesmo aspecto cômico do mundo, estão estreitamente inter-relacionadas e combinam-se de diferentes maneiras. ${ }^{3}$

$\mathrm{Na}$ categoria que diz respeito às "formas dos ritos e espetáculos", o teórico dá ênfase aos festejos na praça pública, levando em conta a comunidade do homem medieval como elemento predominante, opondo-se à seriedade clerical e outras demais autoridades do sistema de pensamento

2 BAKHTIN, Mikhail. Problemas na poética de Dostoiévski. Trad. Paulo Bezerra. $5^{\circ}$ ed. Rio de Janeiro: Forense Universitária, 2010.

${ }^{3}$ BAKHTIN, Mikhail. A cultura popular na Idade Média e no Renascimento: o contexto de François Rabelais. Tradução de Yara Franteschi Vieira. São Paulo. Editora da Universidade de Brasília, 1987, p. 4. 
feudal da época. Esses festejos são denominados como carnaval, festa que não é necessariamente o período anterior à quaresma festejado em muitos locais pelo mundo. Compreende-se por carnaval uma série de festividades que ocorriam durante diversos momentos no ano, isso na Idade Média e no Renascimento. Esses eventos eram sempre associados aos rituais sagrados e a duração dessas festas poderia durar até três meses 4 .

Bakhtin afirma que nos carnavais eram realizadas diversas procissões e celebrações com teor satírico, as quais enchiam as praças durante dias, entre esses festejos ele cita a 'festa dos tolos' (festa stultorum) e a 'festa do asno'; existia também um 'riso pascal' (risus paschallis) muito especial e livre, consagrado pela tradição" 5 . Nessas comemorações, os civis ridicularizavam elementos sagrados da prática Católica Apostólica Romana.

Segundo Soerenses (2008) a palavra carnaval vem etimologicamente de "Karne ou Karth, ou 'lugar santo' (isto é, a comunidade pagã, os deuses e os seus servidores) e de Val (ou Wal) ou 'morto', 'assassinado"' 6 . Assim, compreende-se que tais palavras significam "procissão de deuses mortos", dando-nos a ideia de deuses destronados. Porém, Macedo (2000) considera que "nunca houve no período em questão uma festa denominada 'carnaval', e sim um conjunto de festividades semilitúrgicas ou propriamente profanas (...)", tais atividades dariam origem ao conceito moderno de carnaval, isso após uma série de ressignificações.

O período carnavalesco tendeu a ser fixado nos dias imediatamente anteriores à Quaresma. O próprio termo carnaval, segundo alguns, derivaria do estado de espírito permitido nesses momentos de total liberdade, em que ainda era possível comer em abundância: daí carne vale. Para outros, na origem o nome esteve ligado aos carros alegóricos utilizados nos cortejos e jogos: curris navalis. 0 fato é que, de acordo com o lugar, tais comemorações recebiam designações diferentes, como carnilivari, carnelevarium, carnelevale, carnal, carnestolendas, antruejo 7 .

A respeito da origem da palavra carnaval, Passo (2008) afirma que ela provém do baixo latim carnelevamen, também sendo interpretada como carnis levamen, ou seja, "prazer da carne". Ele também nos orienta para a existência de controvérsias quanto à origem do carnaval, chegando a fazer menção aos cultos realizados na Roma Antiga para festejar a boa colheita, por isso é complexo afirmar se rituais com tais características tiveram um local de surgimento ou se é algo presente em diversas

\footnotetext{
${ }^{4}$ SOERENSEN, Claudiana. 0 mez da grippe: a babel carnavalizada. Curitiba: Universidade Federal do Paraná, 2008, p. 67. (dissertação de mestrado).

${ }^{5}$ BAKHTIN, op. cit., 1987, p. 4

6 SOERENSEN, op. cit., 2008, 68.

7 MACEDO, José Rivair. Riso, cultura e sociedade na Idade Média. Porto Alegre/São Paulo. Ed. Universidade UFRGS/Editora Unesp, 2000, p. 242.
} 
regiões. "Outros historiadores apontam a origem do carnaval no Egito, quando homenagens dirigidas à deusa Ísis e ao deus Touro Apis. Nessas homenagens, os ofertantes dançavam numa grande festa e, as pessoas usavam máscaras" 8 .

Assim, o passar dos anos registra uma pluralidade em relação ao significado da palavra "carnaval" e as divergências em relação aos registros sobre seu aparecimento, sabe-se que na Era Medieval eram festas realizadas em datas comemorativas de deuses pagãos que foram introduzidas no calendário cristão, sendo esses deuses substituídos pelos cânones católicos.

\begin{abstract}
A igreja procurou cristianizar tais cerimônias sacrílegas, substituindo-as, em alguns casos, por festas propriamente cristãs. Nada a estranhar que o Natal viesse a ser comemorado no dia 25 de dezembro, em substituição ás Brumalia, e que as Volcanalia fossem absorvidas pela comemoração em homenagem a São João Batista. Quando ao dia $1^{0}$ de janeiro, em que era celebrada a passagem do ano com festas e mascaradas em homenagem a janus bifronte, os eclesiásticos deslocaram o marco comemorativo do ano novo para o dia da Páscoa. Como a Páscoa é uma festa móvel, já que costuma ser comemorada no domingo seguinte à primeira lua cheia depois do equinócio da primavera, ficava mais difícil qualquer tipo de associação com qualquer festa pagã anterior. De fato, $01^{\circ}$ de janeiro voltou a assinalar o início do ano apenas no século XVI9.
\end{abstract}

Mikhail Bakhtin observou que o carnaval englobava uma série de manifestações populares medievais e renascentistas. Embora não seja um fenômeno originalmente literário, é "um espetáculo ritualístico que funde ações e gestos elaborando uma linguagem concreto-sensorial simbólica" 10 . Nessas festas, o indivíduo participante abria mão de seus hábitos individuais para fazer parte da coletividade da festa, desprovida da hierarquização do regime feudal. Assim, era como se o sujeito possuísse uma segunda vida, na qual novas relações eram estabelecidas em detrimento dos vínculos existentes na esfera extracarnavalesca. Nesse espetáculo, inexiste palco ou diretor, nele todos são atores, mas no caso, não encenam uma determinada peça, eles vivem a encenação sem barreiras sociais, ideológicas, religiosas, ou outras mais; dá-se o fenômeno chamado por Bakhtin de "mundo às avessas", nele o extravasamento proporciona uma liberdade utópica em dias não carnavalescos.

A segunda grande categoria utilizada por Bakhtin para a delimitação da influência popular em Rabelais foram as Obras cômicas verbais, em que o autor evidencia diversas fontes que são classificadas como antigas paródias. Por meio da comicidade encontrada nessas sátiras, identificamos a representação do que ele chama de "concepção carnavalesca do mundo". Essas obras são escritas

8 PASSO, Sônia Maria Dal. Auto da Compadecida: João Grilo e a carnavalização do sagrado. Juiz de Fora: Centro de Ensino Superior de Juiz de Fora, 2008, p. 97. (Dissertação de Mestrado).

9 MACEDO, op. cit., 2000, p. 230.

10SOERENSEN, op. cit., 2008, p. 68. 
em língua vulgar e latina. Nas obras cômicas verbais é possível encontrarmos paródias de hinos, liturgias, evangelhos, orações, testamentos, epitáfios e até mesmo versões paródicas de concílios. "Esse gênero literário quase infinito estava consagrado pela tradição e tolerado em certa medida pela igreja" 11.

Um fato curioso nessa tradição é que nela as fronteiras entre as culturas popular e erudita, criada conjuntamente com a divisão sistemática das classes sociais, são apagadas, pois mesmo que Bakhtin deixe claro a influência popular em relação à prática dos carnavais, essas festividades eram desfrutadas por integrantes de todos as esferas sociais, inclusive a clerical, que foi a grande responsável pela criação, reprodução e preservação desses textos. Bakhtin menciona textos cômicos antigos, como A ceia de Ciprião (Coena Cypriani), a qual foi uma versão carnavalizada da Bíblia, e Vergiliu Maro Grammaticus, obra que parodiava a gramática latina e a filosofia escolástica. Segundo Bakhtin, essas duas obras, escritas na transição entre a Idade Antiga e a Medieval, inauguram a literatura cômica latina medieval, estendendo sua popularidade até o renascimento' ${ }^{12}$. Macedo (2000) reforça a ideia bakhtiniana de que os clérigos alimentaram a literatura cômica, apropriando-se, dessa maneira, de grande parte da herança popular repassada pela oralidade, sendo impossível de ser registrada em um meio no qual o acesso à escrita era restrito à aristocracia e ao clero.

Segundo a interpretação de Mikhail Bakhtin, o riso e as práticas carnavalescas a ele associadas foram banidos da esfera oficial, subsistindo nas tradições exteriores à ideologia oficial da Igreja. Trata-se na verdade, de interpretação bastante genérica. 0 mesmo autor chega a mencionar personagens diretamente vinculados àquela ideologia oficial, como 0 abade Rabano Mauro no século IX ou o bispo de Sens do século XIII, Pedro de Corbeil, envolvidos com a criação ou a reprodução de textos de cunho carnavalesco ${ }^{13}$.

O autor supracitado alega que a tese de Bakhtin não deve ser questionada em sua totalidade. Todavia, alguns aspectos a respeito da cultura popular medieval devem ser reavaliados. Um deles é o fato dele ter descrito boa parte dos elementos da cultura popular com base em fontes do final da Idade Média, contudo "nada indica terem os fenômenos culturais permanecido imutáveis no decurso dos séculos" ${ }^{14}$. Durante toda a investigação Bakhtin utiliza textos do início da Idade Média até o seu final da mesma, porém, atribui-Ihes igual valor no que concerne à cultura cômica popular. De acordo com o próprio Macedo (2000), esses detalhes não abalam a importância da análise realizada por Bakhtin, pois toda pesquisa científica está sujeita a novas descobertas e releituras com o passar dos anos.

11 BAKHTIN, op. cit., 1987, p. 13.

12|bid., 1987, p. 12.

13MACEDO, op. cit., 2000, p. 233.

14lbid., 2000, p. 101. 
As obras cômicas verbais, segundo Soerensen (2008), estão intimamente ligadas às tradições populares produzidas e transmitidas oralmente, sendo muitas vezes materializadas em canções goliárdicas e nos fabliaux. Essa literatura exerceu forte influência em obras como "Decameron, de Boccacio (1349-51), em Contos da Cantuaria, de Chaucer (1386-7-1400) e em 0 elogio da loucura, de Erasmo de Rotterdã (1508)". 15

A terceira subdivisão é o "vocabulário familiar e grosseiro" assimilado nas festas carnavalescas, que rompe com a ordem "oficial" da época, trazendo à tona uma visão carnavalesca do mundo. Essas grosserias eram proferidas não só entre os participantes dos carnavais, mas também às divindades, o que as faz ultrapassar o mero aspecto degradativo, pois ganha também um sentido regenerador e renovador, como a expressão "bosta para ele" (bren pour luy), termo utilizado na época e registra a obra Gargântua.

Esses termos embaraçam leitores ao ponto de dificultar a integração no enredo literário. Bakhtin informa do uso de palavras referentes aos excrementos na literatura no decorrer dos séculos, cita grandes nomes como; Ésquilo em Os ajuntadores de ossos e Sófocles em 0 banquete dos aqueus. As imagens sempre fazem referência a gestos de rebaixamento e ao mesmo tempo uma aproximação com os órgãos genitais, também há o uso de imagens nas quais a ambivalência se faz presente de maneira impactante, como a de uma velha dando a luz, ou seja, o encontro ambivalente entre a vida e a morte; o uso desses recursos literários é chamado por ele de realismo grotesco. A respeito disso (o rebaixamento, a degradação e a regeneração) Bakhtin observa:

$\mathrm{Na}$ base desse gesto e das expressões verbais correspondentes encontra-se um rebaixamento topográfico literal, isto é, uma aproximação do "baixo" corporal, da zona dos órgãos genitais. É sinônimo de destruição, de túmulo para aquele que foi rebaixado. Mas todos os gestos e expressões degradantes dessa natureza são ambivalentes. A sepultura que eles cava é uma sepultura corporal. E o "baixo" corporal, a zona dos órgãos genitais é o "baixo" que fecunda e dá à luz. Por essa razão, as imagens da urina e dos excrementos conservam uma relação substancial com o nascimento, a fecundidade, a renovação, o bemestar. Na época de Rabelais, esse aspecto positivo era ainda perfeitamente vivo e sentido da maneira mais clara ${ }^{16}$

A utilização desse vocabulário por François Rabelais foi uma verdadeira revolução neologística, além de ser um vocabulário capaz de trazer, para o plano material e corporal, figuras

15SOERENSEN, op.cit., 2008, p. 70.

${ }^{16}$ BAKHTIN, op. cit., 1987, p. 127-128. 
divinas, idealizadas. Através do rebaixamento ocorreu o que ele denomina de realismo grotesco, trazendo para o plano da matéria e do corpo tudo aquilo que seja elevado, espiritual, ideal e corporal.

A festa popular, durante os séculos medievais, tornou-se o local onde o riso foi permitido pelas autoridades, pois o mesmo era protegido pela força da tradição, a mesma força que mantém a cultura popular viva durante séculos, sobrevivendo às influências estrangeiras, mantendo os seus caracteres em um estado conservador, inovando-se sem perder os traços mantidos pela tradição perante as novidades estéticas. Os festejos do carnaval não eram distintos somente em relação à vida trivial dos seus participantes, mas também das festas oficiais, nas quais eram preservadas as regras que mantinham a rigidez e a divisão de classes sociais: no carnaval esses valores eram abolidos.

Nesse contexto, a abolição de regras sociais e o nivelamento entre as classes proporcionam uma forma distinta de comunicação, na qual são utilizadas diversas profanações, blasfêmias, obscenidades e diversos insultos; mas essas imprecações possuem uma função ambivalente, por humilhar e libertar ao mesmo tempo ${ }^{17}$. Levando em conta as afirmações de Arruda (2009), o discurso na praça pública apresentava uma linguagem distinta daquela utilizada no cotidiano, aquela usada em ambientes como a Igreja, a corte, as instituições públicas, ou seja, as normas linguísticas impostas pela classe dominante. Um fator característico dessas expressões são as menções utilizadas em relação "ao excremento de urina, de fezes e do salpicar da lama. Estas imagens são ao mesmo tempo bentas e humilhantes e estão ligadas ao riso por serem apresentadas sob o seu lado jocundo e cômico" ${ }^{18}$. Nessa atmosfera carnavalesca, a praça pública tornava-se um local onde as palavras eram dotadas de liberdade, sendo inexistente uma hierarquia entre o sagrado e o profano, pois ambos tinham direitos iguais de representação.

Na praça do carnaval, a distância entre os homens vê-se substituída por um contato livre e familiar. Seu paradigma é o mundo às avessas, que valida todos os travestimentos e inversões de roupas, palavras, atitudes, dando-se voz ao grotesco, ao obsceno, ao que Bakhtin chama de baixo corporal e material, em contraposição à cultura oficial ${ }^{19}$.

Em decorrência de tais acontecimentos, há uma interação entre as culturas erudita e popular, situação na qual elementos de ambas as denominações mostram-se híbridos, havendo dessa forma uma inovação constante na literatura, mesmo que determinados padrões sejam preservados. A respeito do hibridismo cultural, Canclini assegura que as culturas resultam de uma combinação de

17 SOERENSEN, op. cit., 2008, p. 70-71

${ }^{18}$ ARRUDA, Maria do Socorro Araújo. O diabo entrou na igreja: carnavalização do sagrado em "Charivari" de Lourdes Ramalho. Campina Grande. Universidade Estadual da Paraíba, 2009, p. 34. (Dissertação de Mestrado).

19 PASSO, op. cit., 2008, p. 99. 
fontes anteriores a ela ${ }^{20}$. Bakhtin, ao estudar a produção literária de Dostoiévski, classifica 0 desenvolvimento variado do romance como dialógico, sendo determinantes nesse intercâmbio os dois gêneros do que ele chama de sério cômico, o diálogo socrático e a sátira menipeia.

A sátira menipeia recebe tal denominação em razão dos escritos do filósofo Menipo de Gadara, do século III a. C., pois mesmo que a maioria dos seus escritos tenham desaparecido, algumas de sua obras são conhecidas, entre elas uma Necromancia (Nekuia), em que o autor parodia a escrita homérica. Diógenes Laércio compreende que Menipo desenvolveu uma sátira ridicularizadora das tradições literárias do seu tempo. O primeiro a classificar essa literatura como um gênero particular foi o romano Marco Terêncio Varrão, no século I a. C., intitulando-a de Saturae menippeae. "Porém, esse gênero é considerado uma decomposição do diálogo socrático e acredita-se que Antistheno, discípulo de Sócrates, tenha sido seu primeiro representante" 21. Segundo Bakhtin (2000);

Dificilmente poderíamos situar os limites precisos e estáveis desse campo do sério-cômico. Mas os antigos percebiam nitidamente a originalidade essencial desse campo e colocavam em oposição aos gêneros sérios, como a epopéia, a tragédia, a história, e retórica clássica, etc. Efetivamente, são muito substantivas as diferenças entre esse campo e toda a outra literatura clássica antiga22.

A narrativa da sátira menipeia tem o seu foco voltado mais para as atitudes mentais do que para as pessoas, por isso ela "aborda ideias abstratas e teorias, o que a difere do romance convencional" 23 . Assim, os seus personagens são a personificação das ideias que eles representam.

Portanto, essa pluralidade de eventos constitui o que denominamos de carnaval que, mesmo sofrendo uma série de modificações representativas e ideológicas, mantém seu aspecto satírico. termo "Carnavalização" é atribuído ao método desenvolvido por Bakhtin, o qual é utilizado como aporte por diversos pesquisadores para identificar, em grande ou pequena escala, diversas inversões hierárquicas realizadas através da música, pintura ou literatura, muitas vezes realizando uma intertextualidade com fontes tradicionais, transfigurando sua representação inicial e dando-lhe uma significação faceciosa. "Os jograis, num jogo intertextual perpassando pelo espírito lúdico, retomavam e alteravam certas passagens de canções ou romances, imitando-os em contextos ou situações bizarras". ${ }^{24}$

${ }^{20}$ CANCLINI, Néstor Garcia. Culturas híbridas: estratégias para entrar e sair da modernidade. Trad. Heloísa Pezza Cintrão, Ana Regina Lessa. $3^{\circ}$ ed. São Paulo. Editora da Universidade de São Paulo, 2000, p. 200.

21PASSO, op. cit., 2008, p. 100.

22 BAKHTIN, op. cit., 2010, p. 121-122.

${ }^{23}$ PASSO, op. cit., 2008, p. 100.

24 MACEDO, op. cit., 2000, p. 152. 
Essa tipologia textual é importante em vários aspectos. Um deles reside no fato das sátiras expressarem desabafos populares que seriam repreendidos se fossem transmitidos através de uma linguagem pragmática, mas que são protegidos pela comicidade, revelando assim, que as massas populares não são tão omissas como muitos registros historiográficos costumam relatar.

\title{
A Pedra do Reino e a Carnavalização
}

"No domínio literário, a paródia medieval baseia-se completamente na concepção grotesca do corpo" 25. Esse realismo grotesco pode ser encontrado na obra Romance d'A Pedra do Reino de Ariano Suassuna, no Folheto LXX, forma de enumerar os capítulos e possivelmente fazer referência à Literatura de Cordel. No Folheto citado, Arésio dá um soco no bispo, uma autoridade intocável sob a ótica católica, imagem que embora não sendo um exemplo perfeito de realismo grotesco, é uma sobrevivência deste. E Mesmo quando o termo "grosseria" nos remete ao vocabulário popular, as ações de uma determinada trama também podem demonstrar exemplo de rebaixamento de valores oficiais para o plano material e corporal.

\begin{abstract}
Nas grosserias contemporâneas não resta quase mais nada desse sentido ambivalente e regenerador, a não ser a negação pura e simples, o cinismo e o mero insulto; dentro dos sistemas significantes e valorativos das novas línguas, essas expressões estão totalmente isoladas (também o estão na organização do mundo): são fragmentos de uma língua estrangeira, na qual se podia outrora dizer alguma coisa, mas que agora só expressa insultos carentes de sentido. No entanto, seria absurdo e hipócrita negar que conservam um certo encanto, apesar de tudo (aliás, sem nenhuma conotação erótica). Parece dormir nelas a recordação confusa da verdade carnavalesca e de suas antigas ousadias. Não se colocou ainda adequadamente 0 grave problema de sua indestrutivel vitalidade na língua ${ }^{26}$.
\end{abstract}

Além do exemplo de certos vocábulos expostos acima, no Folheto XVII a cena na qual Quaderna vale-se de suas galhofas para disfarçar a falta de habilidade como caçador é exemplar.

-Não atire não, Mestre Dinis! - advertiu-me ele. - Na lagoa, pode ter Marreca, e se você atirar aqui, espanta tudo lá!

Meio humilhado, apelei para a Literatura, para aquilo que Samuel e Clemente chamam, com desprezo, "as saídas de almanaque de Quaderna": - É mesmo! - comentei. - Minha sede de caçador é tanta que, vendo a caça menor, perto, nem me lembrei que podia espantar a

25 BAKHTIN, op. cit., 1987, p. 24.

26 Ibid., 1987, p.25. 
maior! Mas isso é de quem é caçador, mesmo, e, como diz o ditado, "é melhor uma rola na mão do que duas no cu!" 27.

O erotismo em Ariano é presente e compreensível em nossa época, e naturalmente se diferencia daquele utilizado por Rabelais nas épocas medievais. No entanto a comicidade de Suassuna, em muitos momentos, transcende o mero plano satírico e burlesco, podendo nos dar outras significações senão eróticas, pois, por trás dessa lascividade encontramos o herói picaresco e suas peripécias capazes de salvá-lo das mais constrangedoras situações. É possível encontrarmos com a elevação na complexidade da tessitura da narrativa, no Folheto XLVIII, em que Quaderna copula com Maria Safira na igreja.

A confissão acabava. Ela me fez um gesto, indicando-lhe o altar-mor. Havia um espaço vago entre ele e a parede do fundo: ergui-me cuidadosamente, evitando sempre que o velho Padre me visse, e ocultei-me ali, naquele lugar que ela me indicara. Ouvi então os passos do Padre Renato que saía da Igreja, assim como os de Maria Safira, que se aproximavam. Ela chegou para perto de mim e abraçou-me, sempre sem dizer palavra. Todo o seu corpo se achegou ao meu e ela sorriu, notando, pelo contato, que seu gesto sacrílego já obtivera, em mim, o efeito costumeiro contra algum resto de cardina que tivesse ficado no meu sangue. Então, suavemente, como uma onça no cio, deitou-se no chão de tijolo da Igreja e erguei o vestido. ${ }^{28}$

A princípio temos a degradação do ambiente espiritual, mas devemos também levar em conta que Maria Safira, em episódios anteriores foi capaz de curar a impotência sexual Quaderna através de ervas e relações afetivas; portanto, ela não era apenas uma mulher insinuando-se, mas também a responsável e ao mesmo tempo parte da cura de um mal físico que o assolara. Dessa forma não temos o encontro do pecado com o castigo, o que seria comum para o pensamento beato da época, mas do "pecado" com a cura, transgredindo as normas sacras do ambiente em prol de outras alternativas.

Para ratificarmos o realismo grotesco existente na obra de Suassuna, mencionaremos o fato de que Quaderna narra toda a história de dentro da cadeia, mas é justamente nessas condições que ousa considerar-se "rei do quinto império" e ascendente a ser "gênio máximo da humanidade". Assim encontramos o rebaixamento e a regeneração do narrador, para um plano mais respeitoso; dessa maneira, tanto o vocabulário como certas passagens em sua obra são típicos exemplos do realismo grotesco descrito por Mikhail Bakhtin, já que essas regenerações descritas são acompanhadas de

${ }^{27}$ SUASSUNA, Ariano. Romance d'A Pedra do Reino e o Príncipe do Sangue do Vai-e-Volta. $9^{\circ}$ ed. Rio de Janeiro: José Olympio Editora, 2007, p. 124.

28 Ibid., 2007, p. 333. 
inúmeros vocábulos populares, ou seja, neologismo aos "olhos" oficiais, inovação esta que não vem acompanhada de nenhum estigma de inferioridade, mas com o objetivo de ser cada vez mais sublime.

O rebaixamento é enfim o princípio artístico essencial do realismo grotesco: todas as coisas sagradas e elevadas aí são reinterpretadas no plano material e corporal. Já falamos da gangorra grotesca que funde o céu e a terra no seu vertiginoso movimento; a ênfase contudo se coloca menos na subida e na queda, é o céu que desce à terra e não 0 inverso ${ }^{29}$.

As atitudes picarescas acompanham Quaderna no decorrer da narrativa, inclusive nas gravuras, basta observar o "escudo de armas de Dom Pedro Dinis Quaderna30", quando este faz questão de dar destaque aos órgãos sexuais do veado presentes em sua simbologia, na precaução de seu símbolo não ser "mal interpretado", ou seja, não receber conotações homoeróticas. Portanto, essas imagens cômicas acompanham o narrador durante toda a sua trajetória, coroando-se rei e buscando escrever a maior obra literária de todos os tempos.

Assim como Rabelais, Ariano fez uso de um personagem cômico, no caso Quaderna. Isso pode ser comparado ao bufão da Idade Média, não apenas no sentido cômico da palavra, mas como 0 criador de uma nova realidade, como possuidor de uma visão não-oficial do meio em que está inserido, podendo assim trazer novas verdades em detrimento de conceitos oficiais pré-estabelecidos. Na era medieval, o bufão era uma espécie de porta-voz de uma verdade objetiva e possivelmente abstrata, em uma época em que a Europa respirava o cristianismo e as imposições do Estados, e das hierarquias escolásticas, em que as verdades convergiam em direção a esses valores, ficando o meio popular altamente marginalizado ${ }^{31}$.

É válido salientarmos que, apesar da obra de Ariano ter diversos pontos em comum com a obra Rabelaisiana, justamente porque buscam inspiração em fontes populares (apesar de terem passado por uma educação erudita), a diferença cronológica entre elas faz com que a comicidade da Pedra do Reino não tenha em comum tantos outros pontos, como a mesma ambivalência, principalmente porque seria historicamente impossível a ambivalência medieval manter a sua integridade cultural inabalável após tantos séculos (além de tudo, mesmo que a época fosse a mesma, esse sentido ambivalente poderia modificar-se após sua transposição para um espaço social e político radicalmente distinto). 
O século XVI marca o apogeu da história do riso, cujo ponto culminante é o livro de Rabelais. Com a Plêiade, observa-se em seguida uma descida bastante abrupta. Já definimos anteriormente o ponto visto do século XVII sobre o riso: este perdeu seu elo essencial com a concepção do mundo, associa-se à infamação - infamação dogmática esclareçamos -, reduz-se ao domínio particular e do típico, perde seu colorido histórico; sua ligação com o princípio material e corporal subsiste ainda, mas esse próprio princípio é relegado ao domínio inferior do cotidiano ${ }^{32}$.

Assim, poderemos entender o sentido mais amplo de ambas as obras, pois a atemporalidade poderia causar grande distorção no entendimento tanto de uma como de outra. Sabendo que, mesmo em épocas distantes, o diálogo entre as obras permite a escritura e reescritura de determinados caracteres na literatura, além da própria história também ser reescrita, o que traz razões tanto por conta do contexto histórico quanto da tradição literária, para que elementos como a sátira tão presente na carnavalização estejam presente em obras tão distantes temporalmente, mas que revelam a importância que o lúdico pode trazer à literatura.

\section{Considerações finais}

A presente investigação buscou fazer uma conexão entre a ideia de carnavalização proposta por Mikhail Bakhtin e o Romance d'A Pedra do Reino (2007) de Ariano Suassuna. Percebemos que o personagem Quaderna se enquadra na figura rabelaisiana, assim como Gargântua e Pantagruel, personagens picarescos que invertem ordens pré-estabelecidas, rebaixam o divino para o plano material e corporal. Obras como essas também tem a capacidade de diminuir as distâncias entre os estereótipos divididos entre "popular" e "erudito".

Dadas as peculiaridades de cada época, isso possibilita uma visão que não apenas exponha 0 diálogo entre os supostos dois pólos, mas também que exiba manifestações literárias sem as barreiras de entendimentos elencados a partir de pressupostos sociais, com aporte na proposta de Canclini, o qual desconstrói o conceito hierarquizante dos termos em prol de definições ressignificantes, agora pautados não apenas no objeto produzido, mas também nos produtores culturais.

Em sua obra, Canclini apresenta um questionamento pertinente: "Quais são, nos anos 90, as estratégias para entrar na modernidade e sair dela?" 33. 0 enfoque nos agentes sociais que estão em pleno envolvimento com o engendramento dos produtos culturais cultos, populares ou massivos é

\footnotetext{
32 Ibid., 1987, p.87.

33 CANCLINI, op. cit., 2000, p. 17.
} 
pertinente, pois não isola o produto na delimitação do objeto de análise, e sim, envolve-o com seus agentes de produção no contexto em que foi produzido.

Isso permite não apenas compreender as estratégias utilizadas por setores aparentemente bem delimitados, como a cultura de massa voltada para o consumo e a cultura popular, muitas vezes na contramão do consumo, como também possibilita enxergar as ligações entre nichos superficialmente segregados, como o chamado "culto" e o "popular": "Talvez se possa usar este texto como uma cidade, na qual se entra pelo caminho do culto, do popular ou do massivo. Dentro, tudo se mistura, cada capítulo remete aos outros, e então já não importa saber por qual acesso se entrou" ${ }^{34}$. Ao abordar os enlaces entre o que é tradicional e o que é moderno e a visão tradicional daquilo que seria tradicional e moderno, o autor reforça a ideia da América Latina possuir um longo histórico de hibridismo cultural em sua formação sociocultural.

O autor enfatiza que o entendimento recente sobre a constituição acerca da modernidade pode ser resumida a quatro movimentos básicos; projeto emancipador, projeto expansionista, projeto renovador e projeto democratizador. O projeto emancipador dá ênfase às construções autoexpressivas e auto-reguladas das práticas simbólicas e 0 desenvolvimento das mesmas no mercado autônomo. O individualismo e a racionalização das relações sociais integram esse movimento. Compreendemos como projeto expansionista a busca pela modernidade por estender seu conhecimento e o domínio da natureza ao seu redor, além do consumo de bens e a disponibilidade do mesmo no mercado estimulado pelo lucro, para Canclini (2000): "É possível perguntar o que fariam hoje, dentro desse sistema, Leonardo Mozart ou Baudelaire. A resposta é a que um crítico deu: 'Nada, a menos que eles jogassem conforme as regras"' ${ }^{35}$, isso exemplifica 0 fato de que o discurso construído sobre o culto e o popular possui fatores sobrepostos aos motivos estéticos.

Tanto Canclini (2000) quanto Bakhtin (1987), cada qual ao seu modo, apontaram para os termos erudito e popular através de releituras, sem padrões de superioridade ou inferioridade, mas com uma interrelação capaz de desnudar uma possível naturalização de tais conceitos, algo que também se aproxima da proposta do Movimento Armorial de Ariano Suassuna.

O livro de Mikhail Bakhtin, A cultura popular na Idade Média: o contexto de François Rabelais (1987), é uma versão melhorada de sua tese de doutorado. Nele, o autor analisa a presença da cultura popular medieval presente nas obras Gargântua e Pantagruel de François Rabelais. As obras são examinadas perante três subdivisões das diversas manifestações da cultura popular; os ritos e espetáculos, incluindo os festejados em praça pública, as obras cômicas verbais e as formas e gêneros do vocabulário grotesco, trazendo para a obra um neologismo inédito no plano escrito.

\footnotetext{
34 lbid., 2000, p. 20.
}

$35 \mathrm{ld}$. 
As características dos elementos da cultura popular medieval, dando ênfase aos carnavais, dão embasamento para a carnavalização encontrada na obra de Ariano. O personagem Quaderna é um habitante da cidade de Taperoá, interior da Paraíba. Lá ele tem contato com indivíduos das mais diversas orientações culturais, o que enriqueceu ainda mais a sua escrita e intuito de construir um reinado no mundo da literatura, já que no mundo factual não havia possibilidades para isso. 0 desenrolar da narração demonstra nas peripécias do protagonista o rebaixamento do material e corporal, assim como em Rabelais.

Se levarmos em conta a ideia de cultura abordada por Canclini, a reflexão nos faz perceber que a carnavalização é um fenômeno literário presente em momentos distintos no tempo e no espaço. Mesmo que uma comparação fiel incorresse em anacronismo, é possível engendrarmos uma análise da obra de Ariano pautada na análise de Gargântua de Pantagruel, realizada por Bakhtin, pois o lúdico é um elemento forte na cultura popular, algo que proporciona uma nova ótica perante obras consideradas populares ou de inspiração na cultura popular, desnudando a importância de observarmos a literatura marginal e/ou híbrida sob a luz de outros olhares.

\section{Referências bibliográficas}

ARRUDA, Maria do Socorro Araújo. O diabo entrou na igreja: carnavalização do sagrado em "Charivari" de Lourdes Ramalho. Campina Grande. Universidade Estadual da Paraíba, 2009. (Dissertação de Mestrado).

BAKHTIN, Mikhail. A cultura popular na Idade Média e no Renascimento: o contexto de François Rabelais. Tradução de Yara Franteschi Vieira. São Paulo. Editora da Universidade de Brasília, 1987.

BAKHTIN, Mikhail. Problemas na poética de Dostoiévski. Trad. Paulo Bezerra. $5^{\circ}$ ed. Rio de Janeiro: Forense Universitária, 2010.

CANCLINI, Néstor Garcia. Culturas híbridas: estratégias para entrar e sair da modernidade. Trad. Heloísa Pezza Cintrão, Ana Regina Lessa. $3^{\circ}$ ed. São Paulo. Editora da Universidade de São Paulo, 2000.

MACEDO, José Rivair. Riso, cultura e sociedade na Idade Média. Porto Alegre/São Paulo. Ed. Universidade UFRGS/Editora Unesp, 2000.

PASSO, Sônia Maria Dal. Auto da Compadecida: João Grilo e a carnavalização do sagrado. Juiz de Fora: Centro de Ensino Superior de Juiz de Fora, 2008. (Dissertação de Mestrado).

SOERENSEN, Claudiana. O mez da grippe: a babel carnavalizada. Curitiba: Universidade Federal do Paraná, 2008. (Dissertação de Mestrado). 
SUASSUNA, Ariano. Romance d'A Pedra do Reino e o Príncipe do Sangue do Vai-e-Volta. $9^{\circ}$ ed. Rio de Janeiro: José Olympio Editora, 2007. 